\title{
Clonostachin, a Novel Peptaibol That Inhibits Platelet Aggregation
}

\author{
Toshihiro Chikanishi, Keiji Hasumi, Tomotaka Harada, \\ Nobuhide Kawasaki and AKIRA ENDO* \\ Department of Applied Biological Science, Tokyo Noko University, \\ Fuchu, Tokyo 183, Japan
}

(Received for publication August 30, 1996)

\begin{abstract}
A novel peptaibol, designated clonostachin, was isolated from cultures of Clonostachys sp. F5898 by HP-20 and silica gel column chromatographies and reverse-phase HPLC. The structure of clonostachin was determined by Edman and chemical degradations, positive ion FAB-MS, EI-MS, and NMR analyses. Clonostachin was a linear tetradecapeptide with an $N$-terminal acetyl group and a $\mathrm{C}$-terminal sugar alcohol. Clonostachin inhibited ADP-induced aggregation of human platelets by $80 \%$ at $150 \mu \mathrm{M}$.
\end{abstract}

During the course of screening for blood coagulation inhibitors of microbial origin, we have found a novel peptaibol, clonostachin, as an active compound. In this paper, we describe the isolation, structure elucidation and biological activity of clonostachin.

\section{Materials and Methods}

\section{Materials}

Human venous blood was drawn from healthy volunteers in $13 \mathrm{~mm}$ sodium citrate. L-Isovaline (Iva) was purchased from Acros, $\alpha$-amino isobutyric acid (Aib) and ADP were obtained from Sigma. Malt extract agar, oatmeal agar and corn meal agar were purchased from Difco, U.S.A. Czapek-Dox agar was obtained from Eiken chemical, Japan. YpSs agar was prepared as follows: soluble starch (15.0 g) and agar (20.0 g) was dissolved in $400 \mathrm{ml}$ of distilled water by heating in a boiling bath, followed by adding $600 \mathrm{ml}$ of distilled water containing malt extract $(4.0 \mathrm{~g}), \mathrm{K}_{2} \mathrm{HPO}_{4}(1.0 \mathrm{~g})$ and $\mathrm{MgSO}_{4} \cdot 7 \mathrm{H}_{2} \mathrm{O}(0.5 \mathrm{~g})$.

\section{Microorganism}

The producing strain Clonostachys sp. F5898 was isolated from a soil sample collected in Koganei-shi, Tokyo and subcultured on potato glucose agar slants at $25^{\circ} \mathrm{C}$.

\section{Amino Acid Analysis}

Clonostachin $(0.5 \mathrm{mg})$ was hydrolyzed in $6 \mathrm{~N} \mathrm{HCl}$ at $110^{\circ} \mathrm{C}$ for 24 hours. The amino acids released were converted into the $N$-trifluoroacetyl ( $N$-TFA) $n$-butyl ester derivatives as described by PANDEY et $a l^{1)}$. The derivatives were analyzed by GC/MS using a Chirasil$\mathrm{L}$-Val capillary column $(0.25 \mathrm{~mm} \times 25 \mathrm{~m}$, GL-Sciences, Japan).

\section{Trifluoroacetylation}

Clonostachin $(0.2 \mathrm{mg})$ was hydrolyzed in $0.5 \mathrm{M} \mathrm{NaOH}$ at $25^{\circ} \mathrm{C}$ for 18 hours. The mixture was neutralized with $1 \mathrm{M} \mathrm{HCl}$ and evaporated to dryness. The residue was suspended with $0.1 \mathrm{ml}$ of ethyl acetate and incubated with $0.2 \mathrm{ml}$ of trifluoroacetic anhydride at room temperature for 20 minutes $^{2)}$.

\section{Determination of the Configuration of Iva}

Clonostachin $(0.1 \mathrm{mg})$ was hydrolyzed in $6 \mathrm{~N} \mathrm{HCl}$ at $110^{\circ} \mathrm{C}$ for 24 hours. After removing $\mathrm{HCl}$ by evaporation, the resulting amino acids were converted into phenylthiohydantoin (PTH) derivatives as follows. The amino acids were dissolved in $20 \mu \mathrm{l}$ of ice-cold coupling buffer (ethanol - $\mathrm{H}_{2} \mathrm{O}$ - triethylamine - phenylisothiocyanate, $7: 1: 1: 1$, by volume). After incubation at $50^{\circ} \mathrm{C}$ for 10 minutes under nitrogen gas, the mixture was evaporated to dryness at $50^{\circ} \mathrm{C}$ under high vacuum. The residue was dissolved in $30 \mu \mathrm{l}$ of methanol - $\mathrm{HCl}(1: 1$, by volume) and incubated at $50^{\circ} \mathrm{C}$ for 5 minutes under nitrogen gas. The mixture was evaporated to dryness and the resulting $\mathrm{PTH}$-amino acids were fractionated by HPLC on an Inertsil PREP-ODS column $(6 \times 250 \mathrm{~mm}$, GL Sciences, Japan) using $\mathrm{CH}_{3} \mathrm{CN}-10 \mathrm{~mm}$ aqueous sodium acetate, $\mathrm{pH} 4.5(39.5: 60.5)$. The fraction containing PTH-Iva was extracted with ethyl acetate and the organic extract was applied to HPLC on a CHIRALCEL OJ-R column $(4.6 \times 150 \mathrm{~mm}$, Daicel Chemical, Japan). The column was developed with $\mathrm{CH}_{3} \mathrm{CN}-10 \mathrm{~mm}$ aqueous sodium acetate, $\mathrm{pH} 4.5(39.5: 60.5)$ at $40^{\circ} \mathrm{C}$ at a rate of $0.5 \mathrm{ml} / \mathrm{minute}$. The identification of the absolute configuration of Iva was carried out by the co-chromatography with the PTH-derivatives of authentic L- and D,L-Iva.

\section{Platelet-rich Plasma and Platelet-poor Plasma}

Venous blood drawn from healthy volunteers who had not taken any drugs for 2 weeks prior to the study was mixed with $1 / 9$ vol of $0.11 \mathrm{M}$ trisodium citrate. 
Platelet-rich plasma and platelet-poor plasma were prepared by centrifuging blood at $200 \times g$ for 10 minutes and at $2000 \times g$ for 10 minutes, respectively ${ }^{3)}$.

\section{Thromboelastography}

Citrated blood $(300 \mu 1)$ was mixed with $40 \mu \mathrm{l}$ of PBS (150 mM $\mathrm{NaCl}$ and $20 \mathrm{~mm}$ sodium phosphate, $\mathrm{pH} 7.4$ ) containing a test sample. Blood coagulation was initiated by adding $60 \mu \mathrm{l}$ of $1.29 \% \mathrm{CaCl}_{2}$ and the thromboelastograms were recorded at $37^{\circ} \mathrm{C}$ using a TE-700 Clot Tracer (Erma Inc. Japan).

\section{Platelet Aggregation}

Clonostachin dissolved in platelet-poor plasma $(750 \mu \mathrm{l})$ was placed in a disposable polystyrene cuvette. Following incubation at $37^{\circ} \mathrm{C}$ for 5 minutes, $750 \mu$ l of plateletrich plasma were added and the suspension was stirred at $1000 \mathrm{rpm}$ for 5 minutes at $37^{\circ} \mathrm{C}$. The aggregation of platelets was induced by adding $10 \mu 1$ of ADP and the change in turbidity was monitored at $600 \mathrm{~nm}$ at $37^{\circ} \mathrm{C}$ on a Model 320 spectrometer (Hitachi, Japan) ${ }^{\mathbf{3}, 4}$.

\section{General Procedures}

UV spectra were taken on a Hitachi 320 spectrometer. IR spectra were recorded on a Hitachi IR-810 spectrometer. Mass spectra were taken on a JMS-SX102A (JEOL, Japan). NMR spectra were measured on a JEOL LAMBDA 500 spectrometer.

\section{Results}

Taxonomy

Strain F5898 showed slow growth on potato glucose, Czapek-Dox, YpSs, malt extract, oatmeal and corn meal agars at $25^{\circ} \mathrm{C}$, but did not grow at 37 and $45^{\circ} \mathrm{C}$. Colonies on potato glucose agar attained a diameter of $\sim 20 \mathrm{~mm}$ after 7 days at $25^{\circ} \mathrm{C}$. Colonies were plain, initially white, then became powdery and pale cream after prolonged incubations, and partly pale orange to pale brown where conidia and aerial hyphae developed. The reverse of the colony was pale yellow. The submerged hyphae branched irregularly, producing chlamydospores. The conidiophores $(\sim 100 \sim 300 \times 2 \sim 4 \mu \mathrm{m})$ were hyaline, septate, smooth-walled, branched twice to several times penicillately at upper portion and ending in phialides. The phialides $(10 \sim 15 \times 2 \sim 4 \mu \mathrm{m})$ were hyaline, ampulliform, slightly swollen at the base and bent away from main axis. The conidia $(2 \sim 2.5 \times 4 \sim 6 \mu \mathrm{m})$ were hyaline, elliptical or long oval and adhered to each other obliquely, producing long chains $(\sim 100 \mu \mathrm{m})$.

These characteristics of the strain F5898 were closely related to those of Clo. cylindrospora ${ }^{5}$. However, the strain F5898 showed slower growth on malt agar, produced fewer chlamydospores and had smaller conidia than that of the type $(7.0 \sim 8.0 \mu \mathrm{m})$. Thus, this strain was identified as Clonostachys sp. F5898.

\section{Fermentation and Isolation}

The strain F5898 on agar slant was inoculated into a $500-\mathrm{ml}$ Erlenmeyer flask containing $100 \mathrm{ml}$ of medium consisting of $3.5 \%$ glucose, $1.0 \%$ corn starch, $2.0 \%$ soybean meal, $0.5 \%$ peptone, $0.5 \%$ meat extract, $0.3 \%$ $\begin{array}{lllll}\text { yeast extract, } 0.2 \% & \mathrm{NaCl}, 0.05 \% & \mathrm{KH}_{2} \mathrm{PO}_{4}, \quad 0.05 \%\end{array}$ $\mathrm{MgSO}_{4}, 0.01 \% \mathrm{CB} 442$ (antifoam, Nippon Oil and Fat Co., Japan) and cultured at $25^{\circ} \mathrm{C}$ for 3 days on a rotary shaker $(180 \mathrm{rpm})$. One $\mathrm{ml}$ of this seed culture broth was transferred to each of twenty-five 500-ml Erlenmeyer flasks containing $100 \mathrm{ml}$ of the same medium and cultured at $25^{\circ} \mathrm{C}$ for 7 days on a rotary shaker $(180 \mathrm{rpm})$. The cultured broth (2.5 liters) was filtered to separate the mycelium from the broth. The mycelium was extracted three times with $500 \mathrm{ml}$ of acetone. The acetone extract was concentrated to give an aqueous solution, which was then combined with the culture filtrate. The pooled solution (2.4 liters, $\mathrm{pH} 8.0$ ) was adsorbed to a Diaion HP-20 column $(35 \times 210 \mathrm{~mm}$, Mitsubishi Chemical Industries, Japan). After washing with water (1.5 liters), the column was developed with $\mathrm{MeOH}$ (1.5 liters). The active fractions were concentrated to dryness, giving $8.4 \mathrm{~g}$ of an oily residue, which was then applied to a silica gel column $(45 \times 300 \mathrm{~mm}$, Wakogel C-200). After washing the column with dichloromethane-methanol (6:4, 8.4 liters), the active compound was eluted with dichloromethane - methanol ( $5: 5,8.4$ liters). The active fractions were purified by two successive chromatographies on silica gel columns $(15 \times 510 \mathrm{~mm}$ and $15 \times 340$ $\mathrm{mm}$ ) with a solvent system of ethyl acetate-methanol. The resulting active compound $(0.53 \mathrm{~g})$ was further purified by HPLC on an Inertsil PREP-ODS column $(30 \times 250 \mathrm{~mm})$ developed with acetonitrile-water (52.5: 47.5 ) at a rate of $25 \mathrm{ml} /$ minute. Active fractions were concentrated to give an aqueous solution, which was then lyophilized giving $26 \mathrm{mg}$ of purified clonostachin.

\section{Physico-chemical Properties and Structure Elucidation}

The physico-chemical properties of clonostachin are shown in Table 1. The molecular formula of the agent was established to be $\mathrm{C}_{78} \mathrm{H}_{134} \mathrm{~N}_{14} \mathrm{O}_{25}$ from the results of positive HRFAB-MS and NMR spectra and amino acid analysis. The IR absorption bands at $3400(\mathrm{NH})$, 1650 (amide I, CO) and $1540 \mathrm{~cm}^{-1}$ (amide II, NH), the amide proton signals at $6.7 \sim 8.5 \mathrm{ppm}$ in the ${ }^{1} \mathrm{H}$ NMR spectrum and signals in the $\mathrm{CO}$ and $\mathrm{C}_{\alpha}$ region in the ${ }^{13} \mathrm{C}$ NMR spectrum suggested a peptide structure for 
clonostachin. Its negative reactivity with ninhydrin and the presence of a singlet methyl proton at $\delta_{\mathbf{H}} 2.0 \mathrm{ppm}$ in the ${ }^{1} \mathrm{H}$ NMR spectrum indicated the $N$-terminus to be acetylated. Amino acid analysis of the acid hydrolysate (after converting amino acids into $N$-TFA butyl ester derivatives) established the composition of Aib, D, L-Iva, L-Hyp, L-Leu, L-Ile in a molar ratio of $3: 4: 4: 2: 1$. The ratio of D-Iva to L-Iva was $1: 1$ as determined by HPLC on a CHIRALCEL OJ-R column.

The ${ }^{1} \mathrm{H}^{1}{ }^{1} \mathrm{H}$ COSY and $\mathrm{HMBC}$ spectra suggested the presence of a sugar alcohol, which was linked through an ester bond to the carboxyl terminus of the molecule (Fig. 1). The presence of a sugar alcohol was further confirmed by the following experiments. The alkaline hydrolysate of clonostachin was trifluoroacetylated and analyzed by GC/MS on a Chirasil-L-Val column. A peak of a hexa- $O$-trifluoroacetyl sugar alcohol was detected at a retention time of 6.8 minutes. The mass fragmentation pattern of this sugar alcohol derivative was identical to those of hexa- $O$-trifluoroacetyl derivative of mannitol (Fig. 2).

In the positive FAB mass spectrum of the alkaline

Table 1. Physico-chemical properties of clonostachin.

\begin{tabular}{ll}
\hline Nature & White powder \\
Molecular formula & $\mathrm{C}_{78} \mathrm{H}_{134} \mathrm{~N}_{14} \mathrm{O}_{25}$ \\
HRFAB-MS $(m / z)$ & \\
$\quad$ Found: & $1689.9626\left(\mathrm{M}+\mathrm{Na}^{+}{ }^{+}\right.$ \\
$\quad$ Calcd: & 1689.9542 for $\mathrm{C}_{78} \mathrm{H}_{134} \mathrm{~N}_{14} \mathrm{O}_{25} \mathrm{Na}$ \\
IR $v_{\text {max }}(\mathrm{KBr}) \mathrm{cm}^{-1}$ & $3400,1650,1540,1079$ \\
Amino acid composition & Aib (3), L-Hyp (4), L-Leu (2), \\
& L-Ile (1), L-Iva (2), D-Iva (2) \\
\hline
\end{tabular}

hydrolysate of clonostachin, some sequence-specific fragment ions at $m / z$ 128, 241, 354, 453, 566 (B-series) were observed (Fig. 3). From this result, $N$-terminal acyl amino acid residue was assigned to be $N$-acetyl Aib. This residue was released by the treatment with conc. $\mathrm{HCl}$ at $50^{\circ} \mathrm{C}$ for 10 minutes, exposing a new $\alpha$-amino group. This finding enabled determination of the peptide sequence by Edman degradation. Following the first Edman cycle which released $\mathrm{N}$-acetyl Aib, the PTHamino acid derivatives were detected as shown in Fig. 4. A peptide fragment obtained after a 6-cycled degra-

Fig. 1. NMR analyses of the $C$-terminal structure of clonostachin.

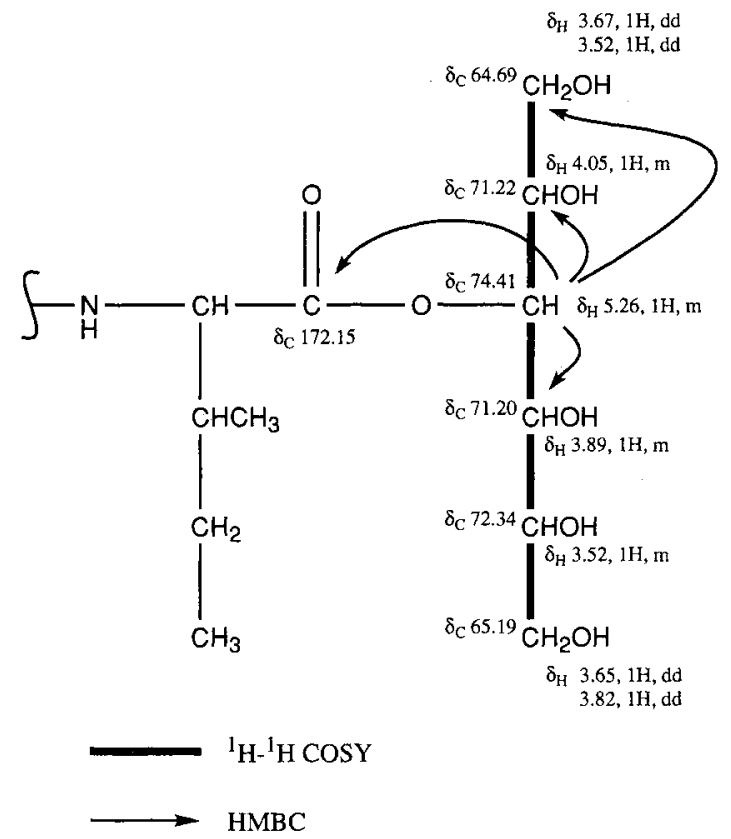

Fig. 2. EI-mass spectrum of the $O$-TFA derivative of the sugar alcohol released by alkaline hydrolysis of clonostachin.

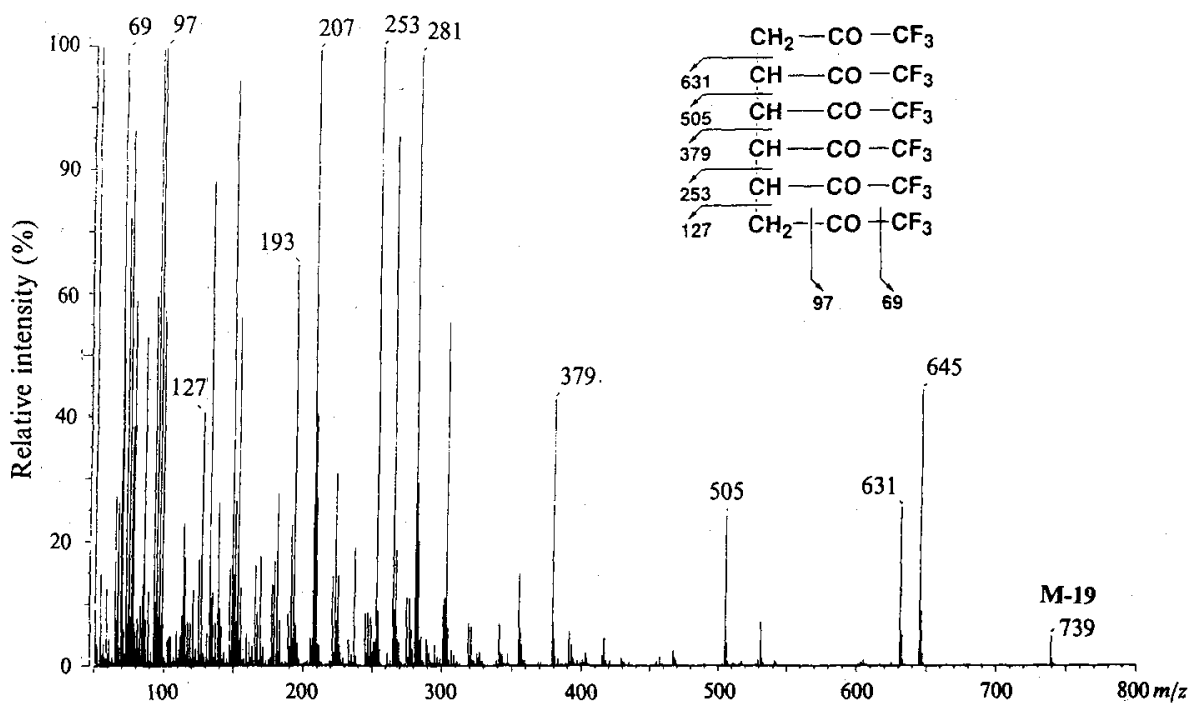


Fig. 3. FAB-MS spectrum of the alkaline hydrolysate of clonostachin.

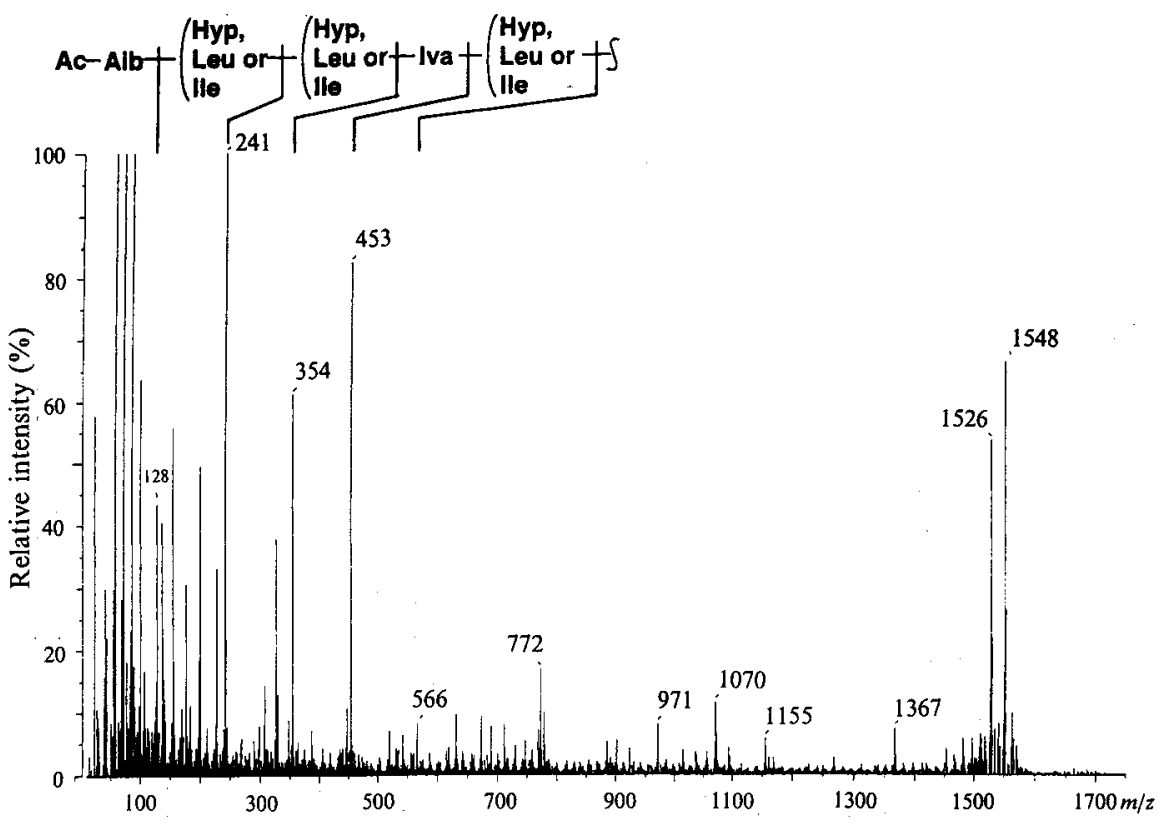

Fig. 4. Edman degradation of clonostachin.

- Hyp, — Aib, O Iva, $\Delta$ Leu, $\nabla$ Ile.

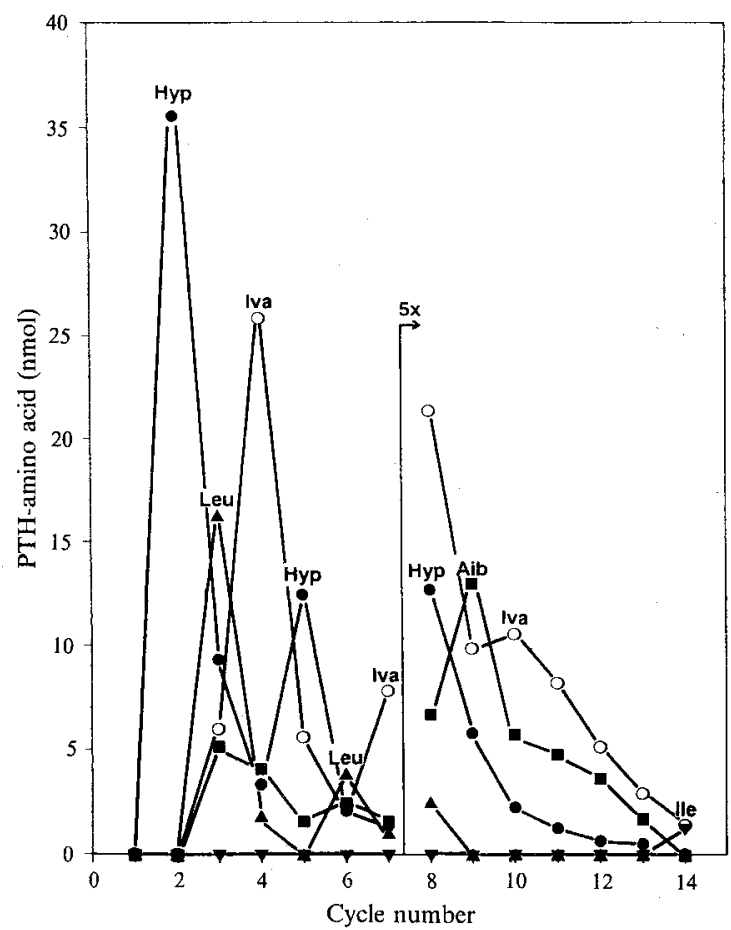

dation showed a protonated molecular ion peak at $m / z \quad 825.5142\left(\mathrm{C}_{39} \mathrm{H}_{69} \mathrm{O}_{11} \mathrm{~N}_{8}\right)$ in the HRFAB-MS spectrum. In addition, the $\mathrm{Y}^{\prime \prime}$-series sequence-specific fragment ions were detected (summarized in Fig. 5).
To assign the positions of two L-Iva and two D-Iva residues, the configuration of Iva released at the 4th, 7th and 10th Edman cycles was determined by HPLC on a CHIRALCEL OJ-R column. The results indicated that Iva was in the $D$ configuration at the 4 th cycle and the $\mathrm{L}$ configuration at the 7 th and 10 th cycles. Accordingly, the remaining Iva (at position 13) was assigned to be in the $\mathrm{D}$ configuration. Thus, the structure of clonostachin was proposed as depicted in Fig. 6.

\section{Biological Properties}

Clonostachin inhibited blood coagulation at a concentration of $50 \sim 100 \mu \mathrm{M}$ as determined by thromboelastography (Fig. 7). In the elastograms, this compound's effect was predominantly on the amplitude, which represents the elasticity of the blood clot. Clonostachin had no effect on the reaction time, which represents the time required for the initiation of clotting. The clotting of platelet-rich plasma, but not of platelet-poor plasma, was similarly inhibited by clonostachin. These results suggested that clonostachin affected platelet aggregation. The effect of clonostachin on the platelet aggregation was investigated turbidimetrically (Fig. 8). At a concentration of $150 \mu \mathrm{M}$, clonostachin inhibited $50 \%$ the reversible aggregation of platelets induced by a low concentration of ADP. Further, the irreversible platelets aggregation, which had been induced by $10 \mu \mathrm{M}$ ADP, was inhibited $80 \%$ by the agent at this concentration. 
Fig. 5. FAB-MS spectrum of the octapeptide derived from clonostachin by a six-cycled Edman degradation.

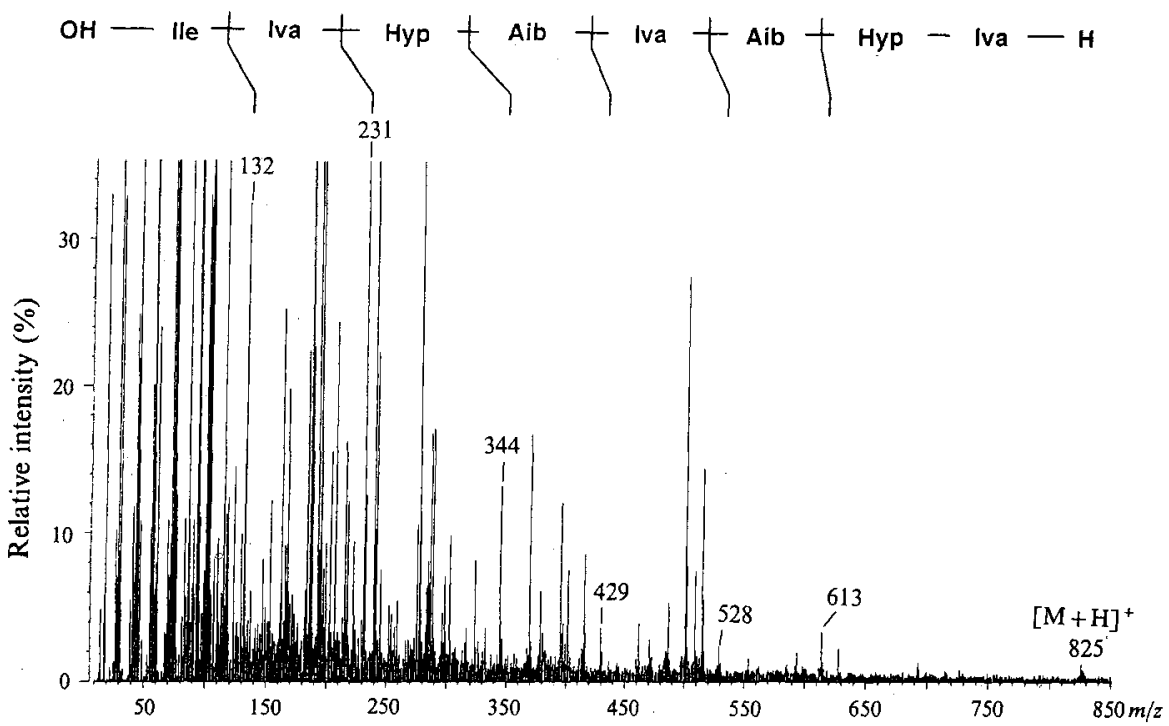

Fig. 6. Proposed structure of clonostachin.

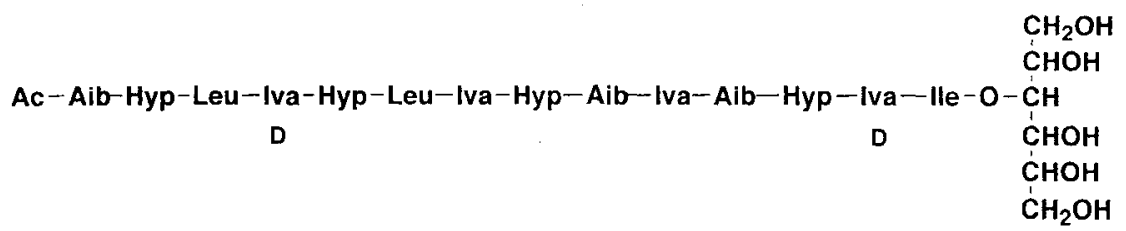

Fig. 7. Effect of clonostachin on the coagulation of whole blood (•), platelet-rich plasma (A) and platelet-poor plasma (ם).

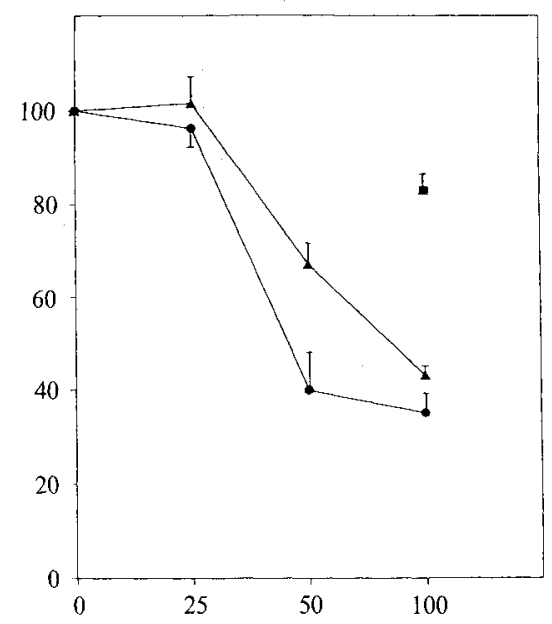

Clonostachin in PBS was added to whole blood, plateletrich plasma and platelet-poor plasma, then blood coagulation was initiated by adding $\mathrm{CaCl}_{2}$. The coagulation was recorded using a thromboelastograph and the maximum amplitude on thromboelastogram was measured. Each value represents the mean \pm S.D. from triplicate determinations.
Fig. 8. Effect of clonostachin on platelet aggregation induced by ADP.

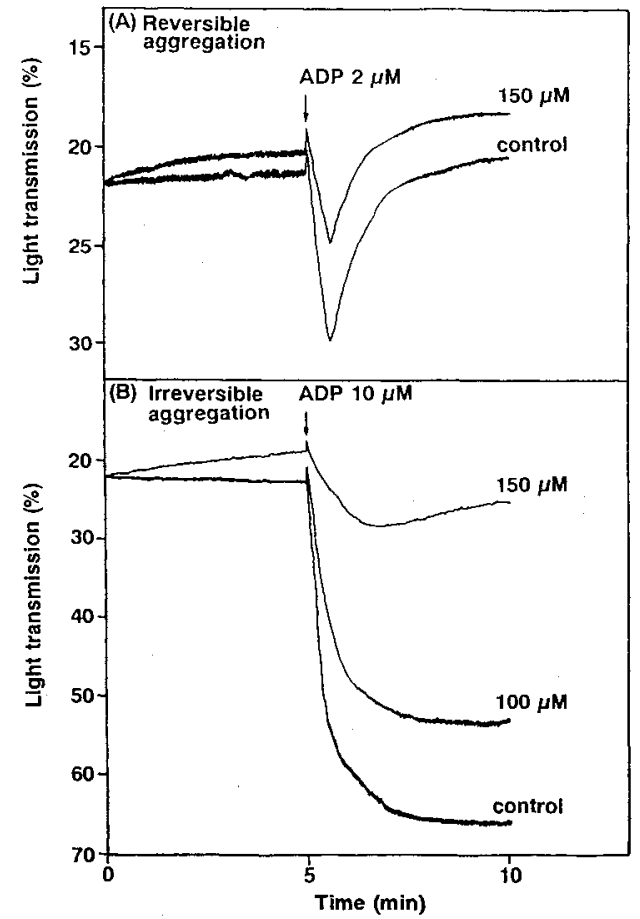

The reversible aggregation was induced by $2 \mu \mathrm{M}$ ADP (A) and the irreversible aggregation by $10 \mu \mathrm{M}$ ADP (B). The spectrometer was adjusted so that platelet-rich plasma has $0 \%$ light transmission and platelet-poor plasma has $100 \%$ transmission. 


\section{Discussion}

Linear peptides containing several $\alpha, \alpha$-dialkylated amino acid residues such as Aib and Iva, an $N$-terminal acyl group and a $C$-terminal amino alcohol are collectively referred to as peptaibols. Although the $C$ terminus of the molecule is an ester-linked sugar alcohol instead of amide-linked amino alcohol, clonostachin has other features of a peptaibol in that it contains seven residues of $\alpha, \alpha$-dialkyl amino acids (Aib and Iva) and an $N$-terminal acetyl group. Thus, clonostachin represents the first member of a new class of peptaibol.

Clonostachin inhibited both reversible and irreversible platelet aggregations. Recently, peptide antagonists for platelet GP IIb/IIIa receptor have been reported ${ }^{6,7)}$. GP $\mathrm{IIb} / \mathrm{III}$ binds fibrinogen and this binding is involved in the mechanism of platelet aggregation ${ }^{8)}$. Since clonostachin does not inhibit the binding of ${ }^{125}$ I-fibrinogen to platelets (data not shown), a mechanism other than GP IIb/IIIa antagonism should be involved.

\section{Acknowledgment}

We thank SHINנI Fujita for helpful comments on the microbial identification, SАтоко Iто for skilful technical assistance and MICHIKo FURUTA for blood drawing.

\section{References}

1) Pandey, R. C.; J. C. CoOK \& K. L. Rinehart, Jr.: High resolution and field desorption mass spectrometry studies and revised structures of alamethicins I and II. J. Am. Chem. Soc. 99: 8469 8483, 1977

2) Ando, S.; T. Ariga \& T. Yamakawa: Identification of stereoisomers of methyl hexopyranosides by mass spectrometry of their trifluoroacetates. Bull. Chem. Soc. Jpn. 49: 1335 1339, 1976

3) ZuCKER, M. B.: Platelet aggregation measured by the photometric method. Methods Enzymol. 169: $117 \sim 133$, 1989

4) Born, G. V. R.: Aggregation of blood platelets by adenosine diphosphate and its reversal. Nature 169: $927 \sim 929,1962$

5) Tubaki, K.: Notes on the Japanese hyphomycetes. I. Chloridium, Clonostachys, Ishmospora, Pseudobotrytis, Stachybotrys and Stephanoma. Trans. Mycol. Soc. Japan 4: $83 \sim 90,1963$

6) Samanen, J.; F. Ali, T. Romoff, R. Calvo, E. Sorenson, J. Vasko, B. Storer, D. Powers, J. Stadel \& A. Nichols: Development of a small RGD peptide fibrinogen receptor antagonist with potent antiaggregatory activity in vitro. J. Med. Chem. 34: 3114 3125, 1991

7) Nicholson, N. S.; S. G. Panzer-Knodle, A. K. Salyers, B. B. Taite, L. W. King, M. Miyano, R. J. Gorczynski, M. H. Williams, M. E. Zupec, F. S. TJoeng, S. P. Adams \& L. P. FEIGEN: In vitro and in vivo effects of a peptide mimetic (SC-47643) of RGD as an antiplatelet and antithrombotic agent. Thromb. Res. 62: 567 578, 1991

8) Calvete, J. J.: On the structure and function of platelet integrin $\alpha_{\mathrm{II}} \beta_{3}$, the fibrinogen receptor. Proc. Soc. Exp. Biol. Med. 208: 346 360, 1995 